\title{
O TEXTO ESCRITO COMO EXPRESSÃO DA SUBJETIVIDADE E DO ESTILO DE ESCRITA NA FASE INICIAL DA ALFABETIZAÇÃO
}

\author{
THE WRITTEN TEXT AS AN EXPRESSION OF SUBJECTIVITY AND WRITING STYLE \\ IN THE INITIAL PHASE OF LITERACY
}

lara Maravalha Freire

Universidade Federal Rural do Rio de Janeiro iaramfreire@yahoo.com.br

\section{RESUMO}

O artigo apresenta resultados de uma pesquisa desenvolvida com crianças do segundo ano do Ensino Fundamental, em uma escola pública municipal do Rio de Janeiro, durante o ano de 2019, tendo por objetivo geral evidenciar, nos textos escritos por crianças, indícios que caracterizam marcas de um estilo de escrita relacionadas à autoria infantil. A análise dos discursos escritos dos sujeitos participantes se fundamentou na teoria da enunciação de Bakhtin, adotando como fundamentação teórico-metodológica para a investigação uma articulação entre as dimensões discursiva e indiciária. Os resultados nos encaminham a afirmar que as crianças, desde o início do processo de alfabetização, trabalham com a linguagem, operando com diferentes recursos linguísticos e expressivos, que revelam marcas singulares, já apontando para um estilo próprio de escrita.

Palavras-chave: Alfabetização; Produção de Textos; Discurso; Autoria; Estilo.

\begin{abstract}
The article presents results of a research with children in the second grade of an elementary public school in Rio de Janeiro during 2019. The aim is to present marks of a style of writing related to child authorship in the texts written by these children. The analysis of the written discourses of the participating subjects was based on Bakhtin's Theory of Enunciation, adopting an articulation between the discursive and the indiciary dimensions as a theoretical-methodological foundation for the investigation. The results lead us to affirm that children, since the beginning of the literacy process, make use of language with different linguistic and expressive resources, which reveal unique marks, already pointing to their own style of writing.
\end{abstract}

Keywords: Literacy; Text Production; Speech; Authorship; Style. 


\section{0 ato de enunciar: 0 estilo e as marcas de autoria}

Podem as crianças durante o processo inicial de alfabetização já revelarem um estilo próprio de escrita? Muitos estudos e pesquisas se dedicam a pensar sobre o processo de autoria infantil, mas pouco ou quase nada se estuda sobre um estilo de escrita durante o processo de apropriação dos conhecimentos da língua. Essa é uma questão ainda a ser discutida a partir do direcionamento do olhar investigativo para a percepção de que as crianças, ao manifestarem seus discursos escritos, mesmo na fase inicial de apropriação da escrita, revelam marcas de autoria, relacionadas ao estilo individual marcado pelas diferentes formas de expressão dos seus conhecimentos de mundo, de seus sentimentos, opiniões e pela forma que enunciam em direção ao outro sujeito, pontuando as distintas maneiras de dizer.

Fundamentados em Bakhtin, afirmamos que, ao estudarmos os enunciados, encontramos as marcas textuais de estilo do gênero e de estilo do autor. O estilo do gênero envolve uma forma de expressão peculiar dele, dada certa circunstância comunicativa discursiva. O estilo do autor é marcado pela sua forma de expressão que caracteriza sua relação valorativa com o conteúdo do objeto e o sentido que quer atribuir ao seu enunciado e, ao mesmo tempo, revela sua singularidade. Essa individualidade se concretiza quando o sujeito autor-criador, não apenas registra os acontecimentos cotidianos, mas, ao produzir seus enunciados, realiza um movimento de refração da realidade a partir de uma posição axiológica. Nessa produção, deixa emergir em seus registros uma escrita viva, criativa, expressiva, que se materializa com base nas diferentes escolhas e na diversidade presente na elaboração dos discursos. Essas opções composicionais das palavras, dos recursos linguísticos e fraseológicos, atuam como expressão valorativa indicando a posição, a entonação e a emoção do autor-criador e acarretam mudanças na construção dos sentidos possíveis a partir dos referidos enunciados.

A escolha das formas sintáticas não é determinada gramaticalmente, mas por considerações estilísticas, isto é, pela representativa e expressiva eficácia dessas formas. Compreendemos [...] que a utilização de formas composicionais diferentes leva a ênfases diferentes nos discursos (BAKHTIN, 2004 apud GOULART, 2016, p. 58).

O autor-criador, ao produzir seu enunciado, se apropria, reconfigura e reorganiza de forma estética as diferentes vozes sociais com as quais ele convive, tomando as palavras alheias a partir de uma valoração e de uma atividade criadora, como palavras suas. Segundo Goulart (2016, p. 57), quando nos apropriamos de palavras dos outros nos processos enunciativos, apropriamo-nos também do tom apreciativo, isto é, das condições sociais em que são produzidas e que têm valor, como processos argumentativos. O autor cria um enunciado novo, singular, de acordo com sua visão de mundo e sua opinião diante dos fatos, utilizando seus próprios meios de expressão. Sua posição é revestida de materialidade verbal e exige um certo distanciamento da linguagem que Ihe é imposta como única, hegemônica e da ideia de que existe uma língua única para significar.

Ao criar o seu discurso, emprega a postura de um olhar excedente de visão e de conhecimento, assumindo como denominado por Bakhtin ([1920-1923] apud FARACO, 2005, p. 41), o princípio esteticamente criativo ou princípio da exterioridade da linguagem. Com esse olhar excedente, o autor se afasta do seu próprio texto e busca vê-lo com um olhar do outro sobre sua própria produção. 
Possenti (2002) postula que as escolhas composicionais, lexicais e demais recursos linguísticos realizadas pelo autor expressam uma determinada concepção de língua, de enunciado e de gênero e estão diretamente relacionadas à singularidade, ao estilo individual do autor, a uma forma de inscrição, de marcar sua presença, seu ponto de vista nos textos produzidos, a uma marca de autoria.

Isso nos leva a compreender que o querer "dizer do autor" envolve tanto o estilo individual, sua forma de enunciar quanto o estilo do gênero discursivo a ser utilizado em acordo com dada situação real de comunicação discursiva.

Como postulado por Bakhtin (2015, p. 282):

a vontade discursiva do falante se realiza antes de tudo na escolha de um certo gênero de discursivo. Essa escolha é determinada pela especificidade de um dado campo da comunicação discursiva. [...]. A intenção discursiva do falante, com toda a sua individualidade e subjetividade, é em seguida aplicada e adaptada ao gênero escolhido, constitui-se e desenvolve-se em uma determinada forma de gênero.

Foi a partir dessa premissa que realizamos uma pesquisa com crianças de uma turma do $2^{\circ}$ ano do Ensino Fundamental, em uma escola municipal do Rio de Janeiro, com o objetivo de compreender que aspectos, nos textos escritos das crianças, evidenciam marcas de estilo relacionadas à autoria a partir das propostas de produção textual realizadas durante o processo de apropriação da leitura e da escrita.

Ao buscar compreender essa questão, outras foram suscitadas como pano de fundo do entendimento do fenômeno do ato criativo das crianças. Assim, tornou-se necessário o conhecimento sobre produção textual, contexto de produção e estilo de escrita. Como se caracterizava o contexto de produção de textos escritos das propostas feitas pela professora? Como compreender as manifestações das marcas de estilo na produção de textos escritos de crianças, tanto individualmente quanto na perspectiva do gênero?

Para responder essas questões tomamos como objeto de análise os textos escritos das crianças, concebendo que os sentidos ali expressos estão diretamente relacionados às condições de produção, às práticas culturais em que as crianças estão imersas e aos níveis de reflexões que conseguem realizar sobre o mundo, a vida e sobre os conhecimentos da linguagem escrita que já possuem.

Entendemos que a produção de textos envolve a utilização de um sistema de referência e a utilização de recursos expressivos que estão em acordo com o querer dizer do autor. "Escrever significa conscientizar-se de sua própria 'fala', ou seja, prestar atenção aos recursos linguísticos mobilizados ou mobilizáveis segundo um projeto dizer definido para o texto em sua elaboração" (GERALDI, 2015, p. 169, grifo do autor).

Geraldi (2011, p. 65) chama a atenção para a necessidade de a escola romper com a prática do exercício tradicional da escrita de redações, a partir de modelos pré-determinados, que apresentam como objetivo primordial a percepção do aprendido pelos alunos com relação a um determinado conteúdo, tendo como fim o espaço da sala de aula e como único leitor o professor. Esse tipo de exercício, por vezes, inviabiliza a atividade de criação e estilo do sujeito-autor, não havendo a percepção de que a linguagem escrita é uma ação criadora impregnada de sentidos e de vida do próprio autor em direção ao seu outro. "Todo trabalho de escritura precisa ser sempre permeado por um sentido, por um desejo, e implica ou pressupõe, sempre um interlocutor no movimento discursivo" (SMOLKA, 2012, p. 95). 


\section{0 princípio dialógico na constituição do enunciado}

Em diálogo com a perspectiva discursiva da alfabetização, o estudo assumiu como base teórica fundante o conceito de linguagem na perspectiva bakhtiniana que afirma que o trabalho de ensino da linguagem escrita somente pode ser concebido a partir de um ato de interação e interlocução.

Assim, a linguagem é concebida como uma atividade humana que se processa dentro de um ato interativo a partir de um evento que envolve sujeitos e um universo discursivo em um dado contexto histórico-social. Os sujeitos realizam ações com a linguagem que se referem aos atos da fala e à elaboração das referências dos fatos, orientadas pelos objetivos pretendidos na enunciação que pode apresentar diferentes modos de enunciar uma mesma realidade, em função de seus interlocutores. Também realizam ações sobre a linguagem que são aquelas que tomam como objetivo principal os recursos linguísticos sem, no entanto, perder de vista o interlocutor e a produção de sentidos.

Para tanto, o trabalho proposto com a escrita deve compreender o caráter social da linguagem, que é uma atividade humana fundamental para o desenvolvimento da consciência individual e social. Nessa perspectiva, os conhecimentos da língua ficam secundarizados em função dos discursos, dos enunciados e dos textos porque aprender a escrever envolve sim conhecimentos inerentes ao sistema alfabético, mas também uma gama de conhecimentos na produção da linguagem escrita com valor e uso social. Como nos declara Goulart:

É importante olharmos para as crianças como leitoras e produtoras de textos e fazê-las sentir que podem, que devem ousar, correr riscos, para que se confirme como pessoas capazes e se disponham a trocar de lugar conosco [...]. Nesse movimento em direção ao outro, afirmamo-nos e confirmamo-nos como educadores comprometidos com o sentido ético, humano, de nossa profissão (GOULART, 2014, p. 172).

Desta forma, pela função social da escola não é mais possível se pensar no ensino da língua sem a atuação criativa das crianças na/sobre a linguagem, fora de um contexto histórico-cultural e sem a compreensão do valor social da escrita. "A noção de trabalho linguístico exige incorporar o processo de produção de discursos como essencial, de modo que não se trata mais de apreender uma língua para dela se apropriar, mas trata-se de usá-la e, em usando-a, apreendê-la" (GERALDI, 2015, p. 153).

A utilização da língua se materializa pelos enunciados orais ou escritos, concretos e únicos que, em suas constituições, trazem características distintas que tornam possível a identificação do campo da atividade humana que eles refletem. Características essas que se referem ao conteúdo, ao estilo da linguagem e a sua construção composicional. O enunciado não é uma convenção, uma unidade apenas de estrutura linguística, mas uma unidade de comunicação discursiva real que se dá no processo de interação ativa entre os interlocutores.

Com essa produção e utilização da linguagem, o homem é um ser social, de discurso, que funda a sua consciência nas relações sociais que estabelece. Quanto mais o sujeito desenvolve sua consciência individual através dessas relações sociais, através de situações reais de vida, melhor ele se apropria e amplia a sua capacidade de utilização da linguagem.

Todas as relações que estabelecemos com o contexto social, no qual estamos imersos, ou com o ambiente natural são mediatizadas pela linguagem, signo e significações. Tais significações surgem com a refração dos signos, sendo elaboradas de acordo com os interesses sociais, o momento histórico e as vivências dos grupos sociais. Cada signo pode assumir uma imensa diversidade de significações de acordo com a consciência socioideológica do contexto sócio-histórico em que está sendo utilizado. 
Não é possível significar sem refratar (FARACO, 2009, p. 51). Essas diferentes significações elaboradas pelos sujeitos são as várias maneiras de dizer o mundo, chamadas por Bakhtin de vozes sociais, que caracterizam o plurilinguismo o qual constitui as relações dialógicas. Nessa interação discursiva, os enunciados são proferidos, tendo um sentido definido e único, de acordo com o todo de cada enunciação.

Ao enunciarmos, realizamos escolhas valorativas das palavras em acordo com a esfera social a que pertencemos considerando a memória discursiva, a resposta presumível e o discurso interior formado de palavras alheias. Como nos afirma Bakhtin, "A palavra é um ato bilateral. Ela é determinada tanto por aquele de quem ela procede quanto por aquele para quem se dirige. Ela é o produto das inter-relações do falante com o ouvinte. A palavra é uma ponte que liga o eu ao outro" (in VOLOCHÍNOV, 2017, p. 205).

\section{0 olhar e a criação de sentidos no encontro com o outro}

A dialogicidade apresentada e discutida por Bakhtin como condição para a produção das subjetividades e de conhecimentos nos levou à compreensão de que, pelo objeto central de análise, o estudo se enquadra no repertório de pesquisas em Ciências Humanas, uma vez que é marcada pela polissemia e pelo princípio da alteridade. Nas Ciências Humanas, o objeto de pesquisa é um sujeito produtor de discurso, sendo o objeto específico da pesquisa o discurso. Foram os discursos escritos das crianças que investigamos. Segundo Bakhtin (1997 apud AMORIM, 2002, p. 10), o que diferencia essa ciência das demais é ter o discurso como objeto específico de pesquisa. $O$ ato de compreensão que tem como base a expressão do sujeito objetivado da pesquisa envolve o conhecimento da palavra, o reconhecimento do seu significado em determinado contexto e a compreensão ativo-dialógica.

Concebendo, de acordo com o pensamento de Bakhtin, que qualquer forma de pensar é incontestavelmente dialógica e compreendendo, como postulado por Goulart (2019, p. 30), a possibilidade de se trabalhar de modo conjugado com duas dimensões teórico-metodológicas, estabelecemos uma relação dialógica entre os pressupostos bakhtinianos e o paradigma indiciário de Carlo Ginzburg (1989).

Assim, assumimos como procedimentos metodológicos as observações das aulas, a entrevista com a professora e o recolhimento e análise dos textos escritos pelas crianças, recorrendo à fundamentação teórica na perspectiva da Teoria da Enunciação e na metodologia do paradigma indiciário de Carlos Ginzburg (1989) como possibilidade de compreensão do ato enunciativo e a percepção de indícios das singularidades, marcados pelos recursos expressivos.

Concordamos com Brait (2005, p. 98) que a concepção de estilo bakhtiniano pode dar margens a muito mais do que a simples busca de traços indicativos de expressividade, mas, por questões metodológicas, tornou-se necessário o elencar de eixos para as análises.

Realizamos análises de produções escritas produzidas pelas crianças, evidenciando as formas de expressão de indícios relativos à posição enunciativa, entendendo que essa posição é decorrente da forma como o autor responde de maneira emotivo-volitiva aos acontecimentos, às vivencias da vida e com base na relação que estabelece com o objeto de sua criação. Buscamos, também, indícios relativos à apropriação das vozes alheias, investigando como foi estabelecida a relação dialógica entre a voz do autor e as vozes alheias no interior do enunciado de acordo com a interação verbal proposta. Bakhtin (1988, apud BRAIT, 2016, p. 121) afirma que: 
[...] em todo enunciado, contanto que examinemos com apuro levando em conta as condições concretas da comunicação verbal, descobriremos as palavras do outro ocultas ou semi-ocultas, e com graus diferentes de alteridade. Dir-se-ia que um enunciado é sulcado pela ressonância longínqua e quase inaudível da alternância dos sujeitos falantes e pelos matizes dialógicos, pelas fronteiras extremamente tênues entre os enunciados e totalmente permeáveis à expressividade do autor.

E, ainda, investigamos a presença explicitada da opinião da criança, sua atitude valorativa sobre um determinado acontecimento, marcando sua posição pessoal sobre o assunto norteador de seu enunciado. Não existe um enunciado sem avaliação. Todo enunciado é antes de tudo uma orientação avaliativa. Por isso, em um enunciado vivo, cada elemento não só significa, mas também avalia (VOLOCHÍNOV, 2017, p. 236).

Essa ação de investigação de autoria nas escritas infantis é bastante complexa visto que, nessa etapa de escolarização em que a pesquisa se efetivou, as crianças ainda estão em fase de construção de um trabalho de elaboração simbólica da linguagem escrita formalizada pela escola, realizando atividades epilinguísticas para se apropriarem do sistema alfabético da escrita.

É importante ressaltar que a escola, historicamente, não tem como práxis olhar para as crianças enquanto sujeitos com formas distintas de aprender e de expressar os diferentes momentos de constituição de seu aprendizado. A escola institui uma forma única, organizada de ensino e, nesta perspectiva, como menciona Smolka (2012, p. 38), a tarefa de ensinar adquire algumas características (é linear, unilateral, estática) porque, do lugar que o professor se coloca (e é colocado), ele se apodera (não se apropria) do conhecimento; pensa que o possui e pensa que sua tarefa é precisamente dar o conhecimento à criança. As crianças devem assumir o papel de alunos que aprendem a ler e a escrever, atendendo ao jogo das representações sociais.

Em seguimento ao exposto, apresento as situações de aprendizagem, contextualizando os eventos e as proposições de trabalho que, discutidas no movimento de interação, indiciaram o uso e as funções da escrita, que antecederam a materialização dos discursos. Posteriormente, analiso as marcas textuais em três textos produzidos por crianças de 7 e 8 anos da turma participante da pesquisa, evidenciando os movimentos de apropriação dos conhecimentos da língua e o desenvolvimento do processo de manifestação de estilo individual na elaboração de sentidos na produção escrita de cada criança.

O texto a seguir é uma reescrita do conto de fadas Rumpelstiltskin do autor Neil Philip. Rotineiramente, logo após o horário de recreio das crianças, a professora realizava a leitura de diferentes contos infantis, sempre negociando com as crianças a história a ser lida. Nesse momento em especial, a professora combinou com a turma que eles iriam assistir a uma contação de história dramatizada a ser realizada pela assistente do Programa Mais Alfabetização . Durante a dramatização, as crianças se mostraram bem entusiasmadas, encantadas e curiosas, uma vez que o conto apresenta um clima de horror, de suspense, o que cria uma certa expectativa do que irá acontecer até o seu final. Ao concluir a dramatização, a professora mobilizou as crianças conversando sobre os acontecimentos dessa narração, aproveitando para estabelecer a relação temática entre outros contos infantis já lidos. Após ampla exploração oral dos assuntos suscitados pelo conto, a professora propôs que as crianças reescrevessem a história, realizando as alterações que desejassem. As crianças poderiam acrescentar personagens, mudar o final da história ou até mesmo poderiam narrar um acontecimento vivido ou ouvido que envolvesse o tema mentira. As crianças produziram com muito entusiasmo, elaborando de forma individual ou com seus pares, trocando ideias sobre a história que desejavam compartilhar. 
Texto 1- A reescrita de Gabrielle

\begin{tabular}{|c|c|}
\hline 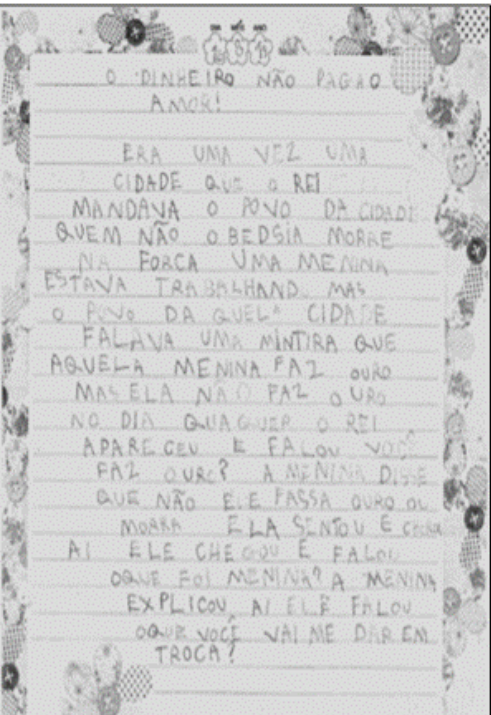 & $\begin{array}{l}\text { Sugestão de leitura: } \\
\text { O dinheiro não paga o amor! } \\
\text { Era uma vez uma cidade em que o rei } \\
\text { mandava no povo da cidade. } \\
\text { Quem não obedecia, morria na forca. } \\
\text { Uma menina estava trabalhando, mas o } \\
\text { povo daquela cidade falava uma } \\
\text { mentira. } \\
\text { Que aquela menina fazia ouro, mas ela } \\
\text { não fazia ouro. } \\
\text { Em um dia qualquer, o rei apareceu e } \\
\text { falou: } \\
\text { - Você faz ouro? } \\
\text { A menina disse que não. } \\
\text { E ele falou: } \\
\text { - Faça ouro ou morra! } \\
\text { El a sentou e chorou. } \\
\text { Ai, ele chegou e falou: } \\
\text { - O que foi menina? } \\
\text { A menina explicou. } \\
\text { Ai ele falou: } \\
\text { - O que você vai me dar em troca? }\end{array}$ \\
\hline
\end{tabular}

Nesse texto, Gabrielle nos revela conhecimentos sobre a escrita convencional, mas por outro lado, ainda não tem total domínio das regras ortográficas. Sabemos da complexidade que envolve o trabalho de escritura, principalmente nessa fase em que a criança está se apropriando de conhecimentos da língua em suas diferentes dimensões. Ela inicia sua narrativa com um discurso já citado, típico das histórias infantis "ERA UMA VEZ" de acordo com o momento de sua enunciação, que narra uma história já acontecida. A partir dos conhecimentos assimilados socialmente, Gabrielle reconhece o papel social que um rei ocupa e, no seu discurso, o empodera, utilizando o verbo no imperativo para a expressão desse personagem. Como pode ser observado ao analisarmos o enunciado "FASSA OURO OU MORRA". Ela cria uma expressividade para os personagens que, em seus discursos, exprimem um certo valor moral e ético, que podemos entender como um comportamento valorado pela autora apreendido culturalmente na interação. Esse fenômeno pode ser observado nos enunciados "A MENINA DISSE QUE NÃO" e "ELA SENTOU E CHOROU". O próprio título "O DINHEIRO NÃO PAGA O AMOR", marcado por uma modalização avaliativa, já nos leva a compreender que sua escolha pode estar diretamente relacionada aos traços da personalidade, do perfil da autora, dos valores morais que vêm se constituindo de acordo com vivências relacionadas à orientação social que recebe. Ao enunciar "MAS O POVO DAQUELA CIDADE FALAVA UMA MINTIRA" e "QUE AQUELA MENINA FAZ OURO MAS ELA NÃO FAZ OURO", Gabrielle utiliza um discurso alheio citado de forma indireta, manifestando o enunciado alheio como forma de expressão dos falantes. Como mencionado por Volochínov (2017, p. 270) o discurso indireto "ouve" diferentemente o enunciado alheio, percebendo-o ativamente e atualizando, na sua transmissão, outros aspectos e tons em comparação com os demais modelos. Também nesses enunciados, podemos observar a utilização de um modalizador, enquanto recurso expressivo para revelação de uma outra posição enunciativa da autora em relação aos discursos alheios. A forma de expressão de Gabrielle nos evidencia traços de estilo autoral no seu trabalho de escritura. Observamos então a presença do autor-criador no texto.

Os dois textos a seguir são relatos pessoais que surgiram em atendimento a proposição feita pela professora, a partir da contação de uma história pertencente ao Caderno do Projeto Espaço de Ser , da unidade 04, página 12, que narra um acontecimento entre o Mascote do Projeto - o boneco Tomás - e sua mãe. Tomás é presenteado com um caminhão que carrega alguns cavalos. Por não ser exatamente o brinquedo que ele havia pedido, Tomás quebra o brinquedo todo. Depois de perceber 
o que fez e o quanto sua mãe ficou triste, o boneco resolve colar as peças do brinquedo e se retrata com sua mãe. A professora explicou que a leitura seria realizada por uma criança e que era necessário que ficassem bem atentos para entenderem melhor a história e para que percebessem quais eram os sentimentos abordados nos diferentes acontecimentos narrados. A menina lia e, à medida que se fazia necessário, a professora realizava mediações, corrigindo e fazendo as entonações orais para melhor compreensão das crianças. Ao finalizar, a professora dialogou com as crianças sobre os diferentes fatos, personagens, sentimentos presentes e estimulou-as a contarem episódios ocorridos com elas que envolveram sentimentos de mágoa, frustração e arrependimento. Após a roda de conversa, a professora propôs que as crianças registrassem por escrito tudo que relataram oralmente. Lembrou que precisavam relatar o que fizeram para magoar uma pessoa, quem foi essa pessoa, onde aconteceu o episódio, como a pessoa ficou e como tudo se resolveu. As crianças começaram a produzir a escrita com muita animação e alguns diziam que nunca tinham magoado ninguém, mas que já tinham sido magoados sim.

Texto 2 - O relato Geisy

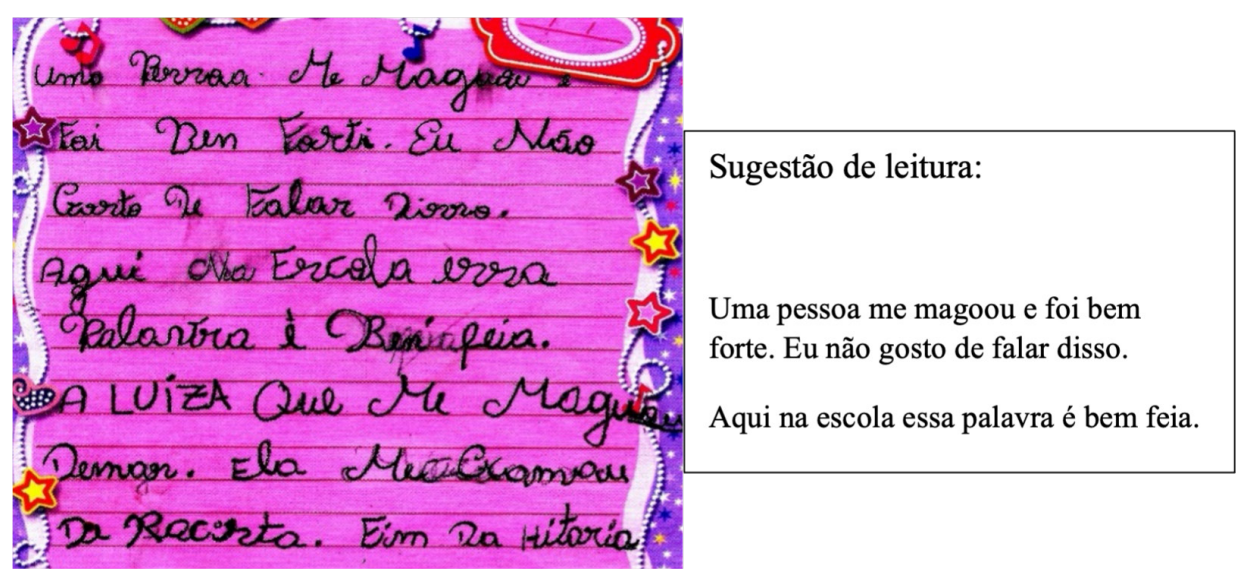

Nesse segundo texto, em atendimento à proposta de elaboração, Geisy assume uma posição avaliativa do comportamento de um outro sujeito diante de sua pessoa. Ao escrever, opera com recursos expressivos de forma a valorizar e acentuar a ofensa recebida e demonstra uma certa dificuldade em relatar o ocorrido e em nomear a colega que lhe magoou. Indícios esses percebidos nos enunciados "EU NÃO GOSTO DE FALAR DISSO" e "UMA PESSOA ME MAGUOU E FOI BEM FORTI". Revela um conhecimento de mundo destacando um comportamento que merece uma reflexão, discussão e enfrentamento considerado como negligente no contexto social e que atual é muito discutido na escola e nas diferentes redes sociais ao declarar "NA ESCOLA ESSA PALAVRA É BEM FEIA" e "ELA ME CHAMOU DE RACISTA". Enfatiza o porquê de sua mágoa e a presença do discurso alheio na constituição de seu comportamento social. O enunciado nunca fala sozinho, ele é incapaz de monologar (CASTRO 2009, apud BRAIT 2016, p. 120). Ainda segundo o autor (2009 apud BRAIT 2016, p. 121), "nesse sentido, o enunciado está sempre refletindo ou refratando ideologicamente a voz alheia, e as formas e as possibilidades dessa realização são inúmeras como são inúmeros os temas". Ainda na expressão "ELA ME CHAMOU DE RACISTA" a menina faz uma transmissão, a partir do seu enunciado, do enunciado de outrem de forma indireta, uma vez que marca de maneira clara o seu dizer e a fala do outro sujeito de forma temática. Nessa produção, foi perceptível como Geisy deixa fluir sua emoção e sensibilidade diante dos acontecimentos cotidianos e como escreve de forma singular marcando seu estilo. 
Texto 3 - O relato de Nicolas

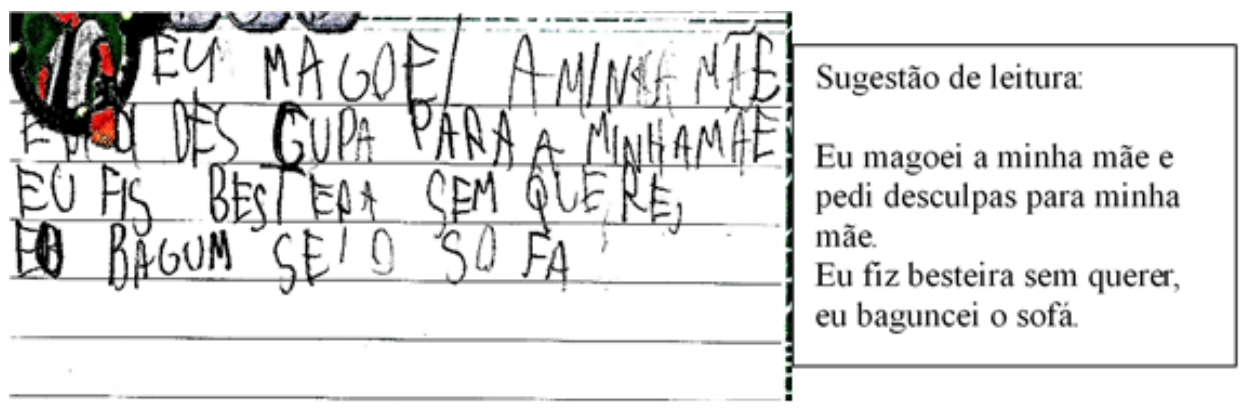

Nicolas, no texto 3, assumindo sua posição enunciativa, relata uma situação que, a princípio, é uma situação cotidiana do universo infantil e familiar. A partir de sua valoração e de outrem, tal situação pôde se tornar objeto de seu enunciado, em resposta à solicitação da produção de texto que era o relato sobre um acontecimento que envolvesse a condição de um sentimento de mágoa.

Analisando esse texto, nos foi possível acreditar que Nicolas tenha passado por um processo de assimilação de um discurso concreto ouvido, de acordo com o episódio acontecido, possivelmente falado por um outro sujeito que tenha um grau de importância e até mesmo de autoridade no seu núcleo familiar.

Ele revela um julgamento e uma valoração de seu ato tendo como base determinadas regras de comportamento a serem seguidas acordadas no movimento de interação entre seus familiares. Seu ato pode ter sido escolhido para responder à solicitação da proposta devido à interação e à interlocução que antecederam o momento de elaboração do texto em que se discutiu sobre o que seja magoar uma pessoa.

Ao expressar "EU MAGOEI AMINHA MÃE", Nicolas marca o evento de forma emotiva e um julgamento social disciplinador do comportamento dos sujeitos, de acordo com a orientação social que recebe. Nesse enunciado fica indiciado a presença, a reação e a referência que outro sujeito tem na formação de Nicolas e na elaboração de sua interação discursiva, apontando o princípio da alteridade bakhtiniana.

Na elaboração de seu texto, Nicolas vai narrando o evento e, ao mesmo tempo, vai expressando o reconhecimento de seu erro, indiciado na expressão "EU FIS BESTERA". Essa expressão poderia ter assumido um caráter de enunciado acabado por apresentar a possibilidade para o leitor de uma total compreensão do que ele fez e uma possível uma resposta ao seu enunciado.

No entanto, o menino julgou necessário expressar o que havia feito de errado explicitando "EO BAGUM SEI O SOFA". Nesse enunciado, ele traz um elemento material real, normalmente utilizado nos ambientes familiares, como forma de complementação do objeto de seu enunciado que permite ao interlocutor presumir em que espaço físico se deu a ocorrência, por pertencerem a mesma comunidade cultural, reafirmando o caráter social de seu discurso. Seleciona a expressão "SEM QUERE" como um recurso para manifestar o sentido extremamente expressivo de arrependimento e pelo tom emocional que deseja dar a seu enunciado.

Nicolas escreve o seu texto apontando para seu leitor, sua forma de retratação utilizada em seu ato, manifestada na expressão "E PIDI DES CUPA PARA A MINHAMÃE". Essa expressão revela um comportamento singular decorrente da relação existente entre a criança com o outro sujeito do enunciado e, também indica uma orientação socialmente estabelecida no grupo social em que vive.

Essa relação que Nicolas busca estabelecer com o seu interlocutor e as escolhas que realiza para concretizar o seu projeto discursivo nos evidenciam o percurso de constituição do seu estilo de escrita. 


\section{Estilo e Autoria nas produções escritas infantis: Discutindo os resultados e as contribuições pedagógicas}

Como se identifica marca de estilo na escrita infantil? Esse foi o escopo da pesquisa. Nos planejamos para analisar os textos escritos buscando identificar indícios que pudessem ser caracterizados como marcas de estilo relacionadas à questão de autoria infantil.

Nossas expectativas giravam em torno do encontro de recursos expressivos utilizados pelas crianças que indiciassem a inscrição de cada autor-criador em seus textos.

Confiávamos que as crianças, em seus textos, utilizavam, embora sem pretensão e de forma bem espontânea, diferentes expressões adquiridas na vida cotidiana, para manifestarem diferentes sentidos nos seus dizeres, caracterizando singularidades e estilos de escrita. Como nos diz Bakhtin (2015, p. 41), "na Linguagem infantil, embora de modo desajeitado, expressa-se a individualidade do autor."

Mas quais as consequências resultantes das observações realizadas? Qual a importância da percepção a que chegamos com relação à existência do desenvolvimento de um estilo de escrita durante o processo de apropriação da língua?

Contemplando os resultados, no limite desse artigo, observamos que as crianças foram se apropriando dos conhecimentos da língua em funcionamento e compreendendo os recursos que poderiam utilizar para ampliar seus enunciados constituídos com um dizer próprio (GERALDI, 2015) de cada sujeito-autor.

As crianças, desde o início do processo de alfabetização, vão trabalhando com a linguagem e, ao realizarem esse trabalho, operam com diferentes recursos linguísticos e expressivos de acordo com os sentidos que desejam expressar em seus discursos, marcando suas singularidades, já apontando para o desenvolvimento de um estilo próprio de escrita. As marcas vão se modificando e se tornando cada vez mais expressiva, à medida que as crianças vão dominando cada vez mais os recursos linguísticos.

O movimento das diferentes crianças durante suas aprendizagens sobre a linguagem escrita revela o grande esforço que fazem para se apropriarem de um objeto cultural tão valorizado socialmente e ao mesmo tempo garantir o seu sucesso na trajetória de autor no contexto escolar. Assim, aprendem a agenciar a solicitação da escola com suas intenções comunicativas, assumindo a função criadora (Bakhtin, 2015) de seus discursos.

A escrita vai relevando e representando a criança, seu modo de sentir, de entender, de agir e de valorar o mundo. Em suas escritas assumem diferentes posições enunciativas e valorativas e trazem de diversos modos as diferentes vozes sociais, reafirmando o princípio de alteridade, que as constituem.

A relevância da nossa percepção sobre como as crianças marcam sua autoria e um estilo próprio de escrita que se constitui, ao mesmo tempo em que vão se apropriando dos conhecimentos da língua e atendendo à perspectiva da escola, se encontra na reafirmação da importância do desenvolvimento de uma prática alfabetizadora embasada na perspectiva discursiva (Smolka, 2012), em que o ensino da escrita ocorra a partir de situações dialógicas, da contação de histórias, da escuta dos discursos das crianças, sendo o processo de ensino organizado a partir de uma observação atenta para o processo de aprendizagem da criança. 
Bakhtin nos leva a compreender que essa possibilidade de desenvolvimento da percepção estilísticas das crianças deve ser desenvolvida a partir de uma metodologia fundamentada na perspectiva dialógica da linguagem, em que professor/aluno, juntos, vão analisando e compreendendo como as escolhas realizadas pelo falante/escrevente enunciam coisas diferentes, ideias diferentes apontando para a compreensão do locutor e a produção de diferentes sentidos (BAKHTIN, 2015, p. 15).

Desta forma, as práticas pedagógicas precisam favorecer que as crianças, na interação com seus pares, elaborem novos conhecimentos, construam e narrem suas próprias histórias, com autonomia para vivenciarem novas experiências na escola e na vida. Que os momentos de produção de textos escritos sejam entendidos como momentos preciosos em que as crianças pensam e analisam a língua e que ao fazerem seus registros escritos, se deixam conhecer através de suas palavras, de seus enunciados, em que exteriorizam os seus saberes, bem como demonstram os aspectos necessários para novas apropriações.

O conhecimento produzido aponta a possibilidade e a necessidade de um trabalho de análise, de uma apreciação nas produções infantis, não só direcionado para os aspectos relacionados à apropriação dos conhecimentos da língua, mas uma observação e discussão sobre as diferentes maneiras de dizer, os estilos individuais que são apresentados nos textos escritos. Dessa maneira, será possibilitada às crianças a compreensão das diferentes formas de expressão, dos efeitos de sentido ocasionados em decorrência das expressões utilizadas e, ao mesmo tempo, a apreensão dos conhecimentos linguísticos, legitimando assim o processo de autoria de cada criança.

Analisando este percurso e a singularidade das crianças, consideramos importante repensar como as práticas de alfabetização funcionam e acontecem nas salas de aula desta cidade e do nosso país.

\section{Referências}

AMORIM, Marilia. Abordagem Sócio-histórica na Pesquisa Qualitativa: Vozes e Silêncio no texto de pesquisa em Ciências Humanas. Cadernos de Pesquisa. n. 116, pp. 07-19, julho/2002.

BAKHTIN, Mikhail. Questões de estilística no ensino da língua. Tradução, posfácio e notas de Sheila Grillo e Ekaterina Vólkova Américo. Apresentação de Beth Brait. Organização e notas da edição russa de Serguei Botcharov e Liudmila Gogotichvíli. 1. ed. São Paulo: Editora 34, 2015. pp. 07-60.

Estética da criação verbal. 6. ed. Trad. Paulo Bezerra. São Paulo: WMF Martins Fontes, 2015 [1979]. Adendo, pp. 161-335, 393-410.

BRAIT, Beth (org.). Bakhtin: Conceitos-chave. 2. ed. São Paulo: Contexto, 2005. pp. 103-119, pp. 151-166.

CASTRO, Gilberto de. Formas sintáticas da enunciação: o problema do discurso citado no Círculo de Bakhtin. In: BRAIT, Beth (org.). Bakhtin e o Círculo. 1. ed. $2^{a}$ reimpressão. São Paulo: Contexto, 2016. pp. 117-135.

FARACO, Carlos Alberto. Autor e autoria. In: BRAIT, Beth (org.). Bakhtin: conceitos-chave. 2. ed. São Paulo: Contexto, 2005.

. Linguagem \& diálogo. Ideias linguísticas do círculo de Bakhtin. São Paulo: Parábola Editora, 2009. Cap. 2 e 3, pp. 84-116, pp. 119-138.

GERALDI, J. Wanderley. O texto na sala de aula. Organizador: Milton José de Almeida. 5. ed. São Paulo: Ática, 2011. p. 117- 131.

. A aula como acontecimento. 2. ed. São Carlos: Pedro \& João, 2015. pp. 29-37, pp. 71-101, pp. 149-153, pp. 165-173. 
Portos de Passagem. $2^{a}$ tiragem. São Paulo: Editora WMF Martins Fontes, 2017. Cap. 1, pp. 1-58. Cap. 3, pp. 135-140. (Coleção Linguagem)

GINZBURG, Carlo. Mitos, emblemas, sinais, morfologia e história. Tradução de Federico Carotti. São Paulo: Ed. Companhia das Letras, 1989. pp. 47-177.

GOULART, Cecília M. A.; WILSON, Victoria (orgs.). Aprender a escrita, aprender coma escrita. 1. ed. São Paulo: Summus, 2013. Cap. 1, pp. 22- 41, Cap. 2, pp. 43-68.

Perspectiva de alfabetização: lições da pesquisa e da prática pedagógica. Raído. Dourados, MS. v. 8, $\mathrm{n}^{\circ}$ 16, jul./dez. 2014.

A escrita de textos por crianças em processo de alfabetização: aprendendo Ciências. EDUEE. Livro 1. Didática e prática de ensino na relação com a escola. 2016.

.; GARCIA, Inez Helena Muniz; CORAIS, Maria Cristina (Orgs.). Alfabetização e discurso: dilemas e caminhos metodológicos. Campinas, SP: Mercado das Letras, 2019.

POSSENTI, Sírio. Indícios de autoria. Perspectiva. Florianópolis, v. 20, n. 1, pp. 105-124, jan. 2002. ISSN2175795X. Disponível em: <https://periodicos.ufsc.br/index.php/perspectiva/article/view/10411/9677> . Acesso em: 7 abr. 2019.

SMOLKA, Ana Luiza Bustamante. A criança na fase inicial da escrita. A alfabetização como processo discursivo. 13 ed. São Paulo: Cortez, 2012. pp. 35-60, pp. 88-140.

VOLOCHÍNOV, V. N. Marxismo e filosofia da linguagem: problemas fundamentais do método sociológico na ciência da linguagem. Tradução, notas e glossário de Sheila Grillo e Ekaterina V. Américo. Ensaio introdutório de Sheila Grillo. 1. ed. São Paulo: Editora 3, 2017 [1926]. Parte I, pp. 91-114, Parte II, pp. 143-238.

Recebido em: 22/06/2021

Aceito em: 15/09/2021 